Research Article

\title{
Experimental Study on Triaxial Unloading Failure of Deep Composite Coal-Rock
}

\author{
Xin Li $\mathbb{D},{ }^{1}$ Hao Li $\mathbb{D}^{1},{ }^{1}$ Zhen Yang $\mathbb{D}^{1},{ }^{1}$ Zhongxue Sun, ${ }^{2}$ Jiayu Zhuang $\mathbb{D},{ }^{1}$ Chongxiao Song $\mathbb{D}^{1},{ }^{1}$ \\ and Xue Wang 1 \\ ${ }^{1}$ College of Electrical and Engineering Control, Liaoning Technical University, Huludao 125105, China \\ ${ }^{2}$ Mine Safety Technology Branch of China Coal Research Institute, Beijing 100013, China \\ Correspondence should be addressed to Hao Li; lntulh@foxmail.com
}

Received 24 December 2020; Revised 24 March 2021; Accepted 26 April 2021; Published 8 May 2021

Academic Editor: Yifei Hao

Copyright (C) 2021 Xin Li et al. This is an open access article distributed under the Creative Commons Attribution License, which permits unrestricted use, distribution, and reproduction in any medium, provided the original work is properly cited.

\begin{abstract}
With the deep mining of coal, the phenomenon of high ground stress is more likely to cause dynamic disaster. In view of the above problems, this paper takes the unloading process of coal mining as the background to study the effects of mining rates under different conditions on the mechanical properties and triaxial failure criterion of composite coal-rock, so as to provide a theoretical basis for the prevention and control of dynamic disasters in coal mines. The composite coal-rock models with a composite ratio of $1: 1: 1$ were tested under different unloading rates or confining pressures. The results show that the triaxial unloading process of coal-rock can be divided into five stages: compaction, single elasticity, elastic-plastic unloading, partial fracture, and complete fracture. In this paper, the failure criterion of composite coal-rock triaxial unloading is derived. The unloading rate has an exponential relationship with the triaxial compressive strength, and the relationship between initial confining pressure and compressive strength is linear. The triaxial compressive strength is determined by both. The peak strains $\varepsilon$ of all samples under different unloading conditions were around 0.01. And initial confining pressure had an influence on the strain variation trend during the unloading of composite coal-rock. The higher the initial confining pressure, the greater the elastic modulus. In addition, an increase of initial confining pressure led to the increase of the total energy converted into dissipated part in the process of fracture and caused the obvious increase of the rebound characteristics of the curve. However, the unloading rate had no influence on the strain trend.
\end{abstract}

\section{Introduction}

The process of coal mining is essentially triaxial unloading process $[1,2]$. With the increasing depth and intensity of coal mining, coal and gas outburst and other coal-rock dynamic disasters occur more and more frequently, which seriously endanger the life safety of underground workers. In order to solve this problem, a large number of scholars in various countries have studied the triaxial test of coal and rock and analyzed the impact of unloading from the comprehensive perspectives of mechanics, electromagnetism, energy theory, and so on. Some results have been achieved so far.

From the perspective of mechanical experimental research, in order to understand the specific characteristics of rock mechanics changes during unloading, Gao et al. designed three triaxial unloading test schemes at different stages and found the characteristics of faster weakening rate of rock during unloading [3]. Under the condition of high stress, Liu et al. carried out a triaxial unloading experiment on raw coal and compared and analyzed the test results, so as to obtain the stress-strain curve and the variation law of mechanical parameters of raw coal during unloading [4]. Their results are helpful for further research. Rong et al. carried out true triaxial unloading experiments on deep rocks under different stress paths, which enabled them to obtain the unloading mechanical characteristic curves and mechanical parameters of rocks under true triaxial unloading conditions [5]. The composite coal-rock samples are essentially combinations of soft and hard phases, so their mechanical properties must be different from that of single 
coal or rock. Zhou et al. studied the interaction of rock cracks under unloading conditions, which showed that the change of crack angle would weaken shear failure [6]. Qin et al. studied the energy evolution and acoustic emission law of sandstone under unloading conditions [7]. It showed that, after the stress peak point of sandstone, the elastic strain energy would quickly be converted into dissipative energy, which leads to rock fracture. $\mathrm{Ni}$ et al. analyzed the acoustic emission characteristics of the triaxial unloading test [8] and verified that the rock after freezing dissolution would produce more cracks and more thorough damage than the conventional ones. Han et al. conducted experiments on rock unloading axial pressure and confining pressure, respectively, and the results showed that the crack inclination angle had the greatest influence, followed by the initial confining pressure, while the unloading speed of radial pressure had a relatively small influence [9]. Wang et al. conducted triaxial compression tests against fatigue cycle restriction on cylindrical marble samples at $0^{\circ}, 30^{\circ}, 60^{\circ}$, and $90^{\circ}$, and the results showed that the fixed direction had a significant effect on the deformation and crack development trend of the marble [10]. Zhang et al. conducted triaxial pressure confining unloading tests on sandy mudstone, and the results showed that sandstone mudstone was damaged and deformed along the unloading direction during the narrow pressure unloading test [11]. In order to determine the relationship between unloading rate and rock mechanical properties, $\mathrm{Li}$ et al. conducted experiments on granite at different unloading rates [12], revealing that unloading rate can only accelerate rock fracture but cannot change the fracture development trend, and rock can only develop along the initial fracture direction. Wang et al. conducted a series of triaxial tests on gas-coal-sandstone assemblages under two unloading conditions [13], and the results showed that the Mohr-Coulomb strength standard is also suitable for gas-coal-sandstone assemblages with unloading stress paths. Taking dolomite as an example, Li et al. studied the unloading damage and permeability characteristics evolution of rock with different confining pressure ratios and pore pressures [14], and the results showed that the strong excavation unloading can lead to the formation of macroscopic failure surface of rock mass and then dramatically increase the permeability.

From the perspective of microtheoretical analysis and simulation, in order to explore the mechanical characteristics of soft and hard phase materials, Li et al. carried out unloading experiments on soft and hard phase rock mass. At the same time, Solidworks software was used for simulation. After that, the results of the two were compared and analyzed to obtain the mechanical parameter characteristics of rock mass under different confining pressures [15]. In addition, Sun et al. used CT imaging technology and threedimensional reconstruction method to establish threedimensional models of different coal and rock states and then revealed the effects of unloading, intermittent joints/ fractures on mechanical properties, and failure mechanism of coal and rock [16]. Cai et al. used FLAC ${ }^{3 \mathrm{D}}$ numerical simulation to conduct a numerical simulation of the entire deep coal strata [17] and studied and verified the overall stress distribution and deformation characteristics of the coal strata during the mining of the protective layer. $\mathrm{Ni}$ et al. studied the failure characteristics of tunnel rock in the cold region by triaxial experiment and electron microscope imaging [18] and revealed that the cause of rock failure in the cold region was freeze-thaw rather than triaxial stress. Zhu et al. studied the mechanical properties and acoustic emission characteristics of bedrock with different narrow pressures and positions [19], and the results showed that, with the increase of pressure applied to bedrock, although the shear failure angle decreased, the peak stress and fatigue life of the rock increased significantly. Wu et al. used the finite element method to model the deep rock unloading process, and their model contributed to the further study of rock unloading [20]. Zhou et al. studied the interaction between cracks in the rock mass and conducted numerical simulation using the dislocation model, and the results showed that the interaction between cracks was more prominent under axial unloading [21]. Sun et al. conducted a numerical simulation test of unloading failure based on the numerical method combining RFPA and DDA [22], and the results showed that rock stability and material properties had a great influence on rock fracture, and fracture expansion was predictable to a certain extent.

From the perspective of energy theoretical analysis, Yang et al. studied the law of energy variation of rock and coalrock by using a triaxial unloading experiment, which laid a foundation for coal power disaster prevention and control [23-25]. Fan et al. studied the energy attenuation law of stress waves of different frequencies and forms propagating in rocks and other materials under unloading state and confirmed that unloading behavior has an important influence on energy transmission of both monopulse and multipulse stress waves [26]. Wang et al. carried out a triaxial unloading experiment on underground marble and analyzed its mechanical trend in the unloading process from the perspective of energy by using the samples after the CT scan experiment [27]. They believed that energy dissipation and release depended on unloading rate and time. Zhang et al. conducted triaxial experiments on rock using axial load and lateral deformation control mode [28] and established energy conversion equations at different stress-strain stages. Yang et al. carried out a triaxial unloading test on sandstone with pressure limitation [29] and found that the higher the initial confining pressure was, the more energy the sandstone stored and the more serious the fracture damage was. Huo carried out uniaxial, triaxial, and triaxial unloading experiments on coal-rock, studied the acoustics and deformation fracture mechanism at the time of fracture [30], and proposed the fractal dimension value to accurately describe the evolution law of internal cracks in coal-rock.

In summary, it can be found that although there are many researchers on this problem, most of them only study the triaxial loading mechanical process of a single coal sample or rock sample. Or most of the literature studies only carry out triaxial loading test, lacking unloading process test. Moreover, there are few reports on the study of mechanical change law under the simulated actual mining process. In addition, studies on the triaxial failure criterion of composite 
coal-rock are few now, and most of them are only analyzed from the perspective of mechanics but seldom analyzed in combination with unloading condition parameters, which makes it difficult to judge the mining status of coal-rock in actual engineering. Therefore, it is urgent to establish the triaxial failure criterion of composite coal-rock based on unloading parameters.

The composite coal and rock with a volume combination ratio of $1: 1: 1$ were studied in this paper, and triaxial unloading tests were carried out under different unloading rates and confining pressures with the triaxial testing instrument. In this paper, the trend and law of stress-strain variation of composite coal-rock during triaxial unloading were studied, and the influence of different unloading rates and initial confining pressure on triaxial compressive strength was analyzed. In addition, this paper also studied the triaxial failure criterion of composite coal-rock based on unloading parameters. The research results of this paper have certain theoretical and practical significance for preventing rockburst in coal and rock dynamic disasters.

\section{Tests and Results}

2.1. Test Samples and Equipment. In the actual coal mine, the coal seam is mostly sandwiched in the rock layer, which basically presents the three-layer structure of "rock-coal-rock". According to this characteristic, the composite coal and rock samples used in the test are processed. The coal and rock samples in this test were taken from a deep coal seam in Inner Mongolia, and the roof and floor rocks of the samples were sandstone. In the laboratory, in strict accordance with the experimental requirements of the International Society of Rock Mechanics [31] and previous experience [32,33], the roof rock sample, coal sample, and floor rock sample are processed and combined into standard cylinder specimens with the volume combined ratio of $50 \mathrm{~mm}$ in diameter and $100 \mathrm{~mm}$ in height of $1: 1: 1$. The structure and size of the test samples are shown in Figure 1.

The TAW-2000 triaxial testing machine was used for the triaxial test. The test equipment and site are shown in Figure 2. It can be seen from it that the experimental equipment mainly consists of rock mechanics loading system, strain sensor, confining pressure cylinder, oil box, control power cabinet, and computer. The confining pressure in the experiment can be controlled by the oil inlet valve and outlet valve of the oil tank. The strain sensor and the rock mechanics loading system monitor the stress and strain data in the loading process of composite coal-rock in real time and upload data to the computer for preservation, which is convenient for subsequent processing and analysis.

2.2. Test Steps. The test consists of triaxial loading pretest and unloading test. The purpose of the preliminary test is to determine the starting point of unloading in the unloading test, and the starting point of triaxial unloading is $70 \%-80 \%$ of the normal triaxial compressive strength [33].

The pretest steps are as follows:

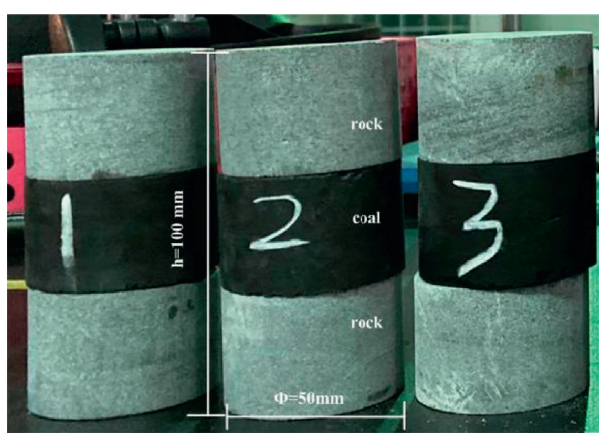

FIgURE 1: Sample structure and size.

(1) The composite coal-rock samples were sealed with heat shrinkable tubes and strain sensors were installed on the outside. Then put the combined samples into the pressure cylinder and push the pressure cylinder into the test instrument. After that, the oil valve was opened to inject silicone oil, and the oil valve was closed when it was full.

(2) The power supply was turned on and three-way stress was applied according to the static horizontal pressure condition $\sigma_{1}=\sigma_{2}=\sigma_{3}$ to the predetermined confining pressure value.

(3) Pretest was carried out according to the conventional triaxial loading method. During the loading process, the confining pressure $\sigma_{3}$ was kept constant. Meanwhile, the displacement control method was adopted to load at the rate of $0.002 \mathrm{~mm} / \mathrm{s}$. When the axial stress crossed the stress peak, the test was stopped immediately and the axial stress peak was recorded.

The unloading test steps are as follows:

(1) The procedure was the same as the preexperiment procedure (1) and (2).

(2) Keep the confining pressure $\sigma_{3}$ constant and loaded at a rate of $0.002 \mathrm{~mm} / \mathrm{s}$ by using displacement control mode. When the axial pressure $\sigma_{1}$ reached about $70 \%$ of the compressive strength under conventional triaxial loading, the confining pressure relief operation should be started immediately.

(3) During unloading operation, the axial pressure should be maintained to continue loading, and the confining pressure should be discharged at a certain rate to gradually reduce it. According to references $[4,5,34,35]$, the unloading rate during triaxial unloading is not greater than $0.3 \mathrm{MPa} / \mathrm{s}$, no matter the experimental object is coal or rock. Combined with the previous foundation and considering the experimental gradient, the study set the unloading rate of $0.05 \mathrm{MPa} / \mathrm{s}, 0.1 \mathrm{MPa} / \mathrm{s}$, and $0.2 \mathrm{MPa} / \mathrm{s}$ to simulate the slow, medium, and fast unloading conditions in the actual situation.

(4) When the axial stress exceeded the stress peak and the sample was damaged, the confining pressure relief operation should be stopped immediately. 


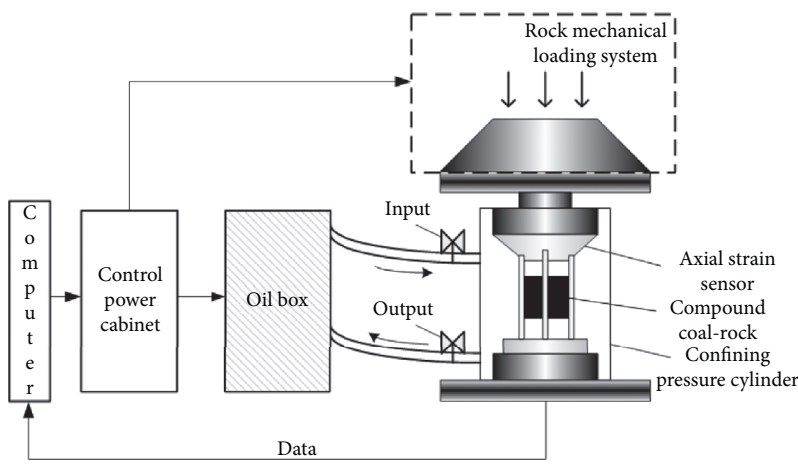

(a)

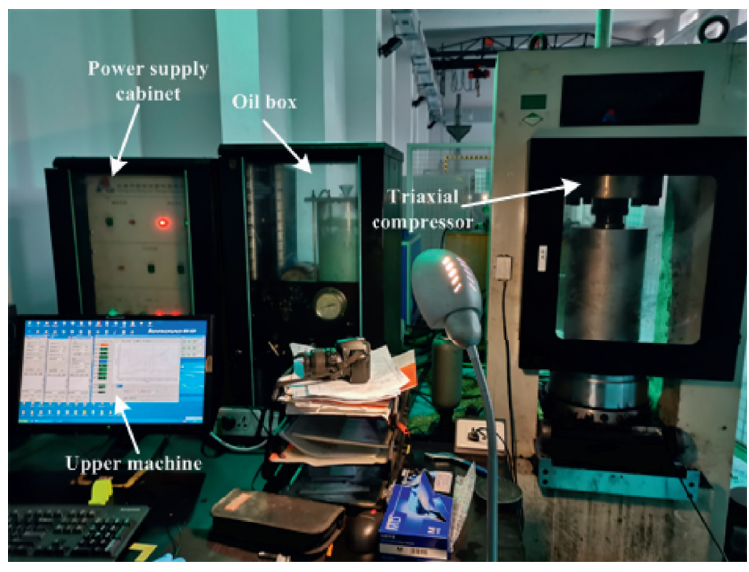

(b)

Figure 2: Test equipment and the scene. (a) Laboratory equipment. (b) Test on site.

After that, the confining pressure remained unchanged and axial stress was continuously applied until the stress curve no longer changes with the strain; then, the test was over.

The predetermined confining pressure values in this test are three groups: $10 \mathrm{MPa}, 15 \mathrm{MPa}$, and $20 \mathrm{MPa}$. Prepare 21 groups of composite coal-rock samples, whose functions are as follows: three groups of samples were used for pretest, which were used to measure the triaxial compressive strength of coal-rock under three kinds of confining pressures; triaxial unloading tests were carried out on 9 groups of samples at the unloading rates of $0.05 \mathrm{MPa} / \mathrm{s}, 0.1 \mathrm{MPa} / \mathrm{s}$, and $0.2 \mathrm{MPa} / \mathrm{s}$ under the same confining pressure of $10 \mathrm{MPa}$; and nine groups of samples were tested at the confining pressures of $10 \mathrm{MPa}, 15 \mathrm{MPa}$, and $20 \mathrm{MPa}$ at the same rate of $0.1 \mathrm{MPa} /$ s. Under the same conditions, three groups of the six unloading tests were carried out to obtain the best effect. If the three groups of the same condition did not have a good effect, they should be supplemented.

2.3. The Test Results. The results of the three groups of preliminary tests are shown in Table 1. The triaxial compressive strength of the three groups of samples is recorded in the test, and the $70 \%$ strength value is calculated to determine the unloading starting point for the subsequent unloading test. According to the calculation, when the composite coal and rock samples are tested under the conditions of $10 \mathrm{MPa}, 15 \mathrm{MPa}$, and $20 \mathrm{MPa}$ respectively, unloading should start near $36.398 \mathrm{MPa}, 47.778 \mathrm{MPa}$, and 56.650 MPa.

The unloading test was carried out in combination with the results of the preliminary test. From the results of six different conditions (a total of 18 groups) of composite coalrock triaxial unloading test, one group of results with characteristics was selected, respectively, whose data were close to the average value and have little dispersion and curve had obvious stages. Then, they were numbered by $1 \# \sim 6 \#$. Samples $1 \#$ to $3 \#$ were unloaded at different rates $(0.05 \mathrm{MPa} / \mathrm{s}, 0.1 \mathrm{MPa} / \mathrm{s}$, and $0.2 \mathrm{MPa} / \mathrm{s})$ under the condition of $10 \mathrm{MPa}$ confining pressure, whose parameters and results are shown in Table 2 . In addition, samples from $4 \#$ to $6 \#$ were unloaded at $0.1 \mathrm{MPa} / \mathrm{s}$ under different confining pressures (10 MPa, $15 \mathrm{MPa}$, and $20 \mathrm{MPa})$, whose parameters and results are shown in Table 3.

\section{Failure Criterion of Composite Coal- Rock under Unloading Condition}

3.1. Relationship between Unloading Rate and Triaxial Compressive Strength. Figure 3 shows the stress-time curve of the triaxial test at $0.05 \mathrm{MPa} / \mathrm{s}, 0.10 \mathrm{MPa} / \mathrm{s}$, and $0.20 \mathrm{MPa} / \mathrm{s}$, respectively, under the same $10 \mathrm{MPa}$ confining pressure, as well as the trend curve of the change in compressive strength of the 9 groups of tests under the confining pressure.

Figure 3(a) shows the stress-time curve of samples $1 \# \sim 3 \#$. It can be seen that the change of unloading rate has no significant influence on the overall trend of axial stress change. The whole stage can be divided into five stages, the first two of which are conventional loading stage and the last three are unloading stage. Taking the stress-time curve of 2\# sample as an example, the stages of mechanical changes in the unloading process are described as follows:

(1) Compaction phase (O-A segment): it can be seen from the curve in Figure 2(a) that there is no definite relationship between axial stress and time at this stage, and the curve shows a series of small fluctuations with extremely short duration. The composite coal-rock is a composite material, and there are some protogenetic fine cracks in it. During the loading, these cracks are compressed tightly due to the threeway stress, which leads to the nonlinear change of axial stress with time. In addition, because they are extremely small, the duration of this stage is relatively short.

(2) Single elastic stage (A-B segment): this stage is between the end of the compaction stage and the starting point of unloading. It can be seen from the curve that there is a linear relationship between axial 
TABLE 1: Preliminary test results.

\begin{tabular}{lccccc}
\hline Sample number & Height $(\mathrm{mm})$ & Diameter $(\mathrm{mm})$ & Confining pressure $(\mathrm{MPa})$ & $\begin{array}{c}\text { Compressive strength } \\
(\mathrm{MPa})\end{array}$ & $\begin{array}{c}\text { 70\% of compressive strength } \\
(\mathrm{MPa})\end{array}$ \\
\hline Pre-1\# & 101.640 & 49.540 & 10.000 & 51.997 & 36.398 \\
Pre-2\# & 101.320 & 49.600 & 15.000 & 68.257 & 47.778 \\
Pre-3\# & 101.520 & 49.640 & 20.000 & 80.929 & 56.650 \\
\hline
\end{tabular}

TABLE 2: Unloading test results at different rates.

\begin{tabular}{lccccc}
\hline Sample number & Height $(\mathrm{mm})$ & Diameter $(\mathrm{mm})$ & Unloading rate $\left(\mathrm{MPa} \cdot \mathrm{s}^{-1}\right)$ & Fracture load $(\mathrm{kN})$ & Compressive strength $(\mathrm{MPa})$ \\
\hline 1\# & 97.580 & 49.540 & 0.050 & 98.052 & 50.910 \\
2\# & 98.880 & 49.520 & 0.100 & 91.972 & 47.715 \\
3\# & 101.520 & 49.640 & 0.200 & 90.932 & 46.985 \\
\hline
\end{tabular}

TABLE 3: Different confining pressure unloading test results.

\begin{tabular}{lccccc}
\hline Sample number & Height $(\mathrm{mm})$ & Diameter $(\mathrm{mm})$ & Confining pressure $(\mathrm{MPa})$ & Fracture load $(\mathrm{kN})$ & Compressive strength $(\mathrm{MPa})$ \\
\hline $4 \#$ & 101.240 & 49.540 & 10.000 & 87.696 & 45.497 \\
5\# & 101.040 & 49.380 & 15.000 & 120.882 & 63.120 \\
6\# & 101.840 & 49.820 & 20.000 & 154.718 & 79.368 \\
\hline
\end{tabular}

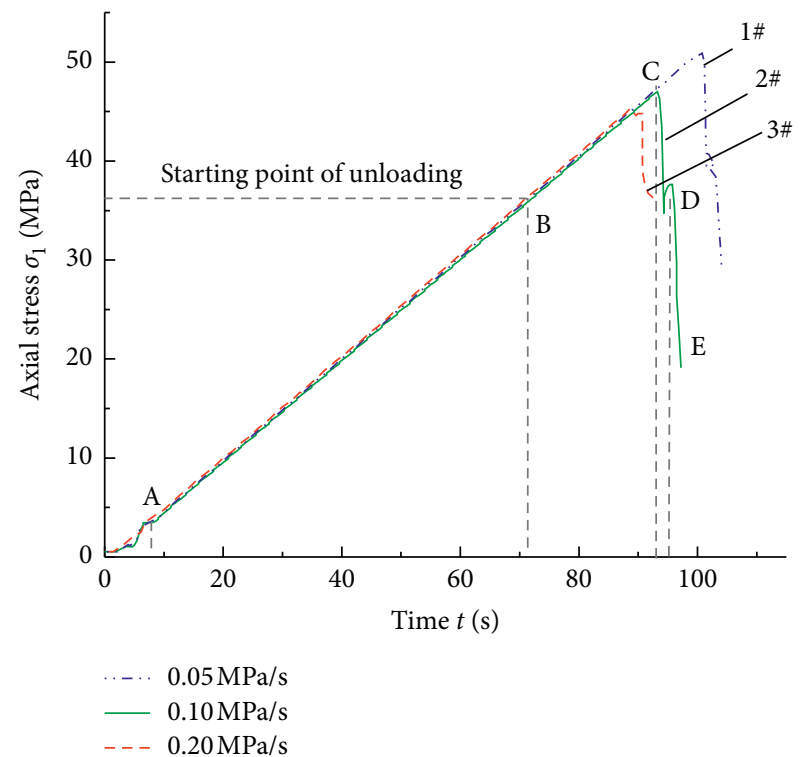

(a)

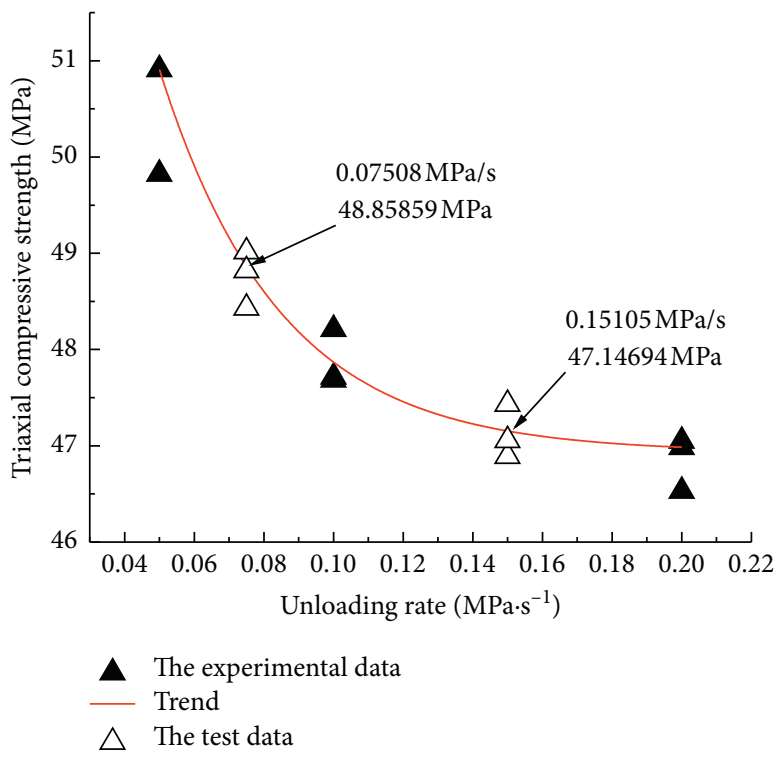

(b)

FIGURE 3: Stress path and compressive strength at different unloading rates. (a) Stress paths of $1 \# \sim 3 \#$ samples. (b) Triaxial compressive strength fitting curve.

stress and time at this time, and only elastic deformation occurs in the whole stage of the composite coal-rock.

(3) Unloading elastic-plastic stage (B-C segment): when unloading begins, the coal-rock samples enter this stage and end at the peak of axial stress. In the early stage, the axial stress is still linearly related to time and is the same as that in the B-C segment. This proves that the deformation of it at this time is still elastic deformation and unloading operation does not affect the linear relationship between time and stress. In the early stage of axial stress peak (point C), a very short region can be seen on the stress-time curve. The axial stress shows a nonlinear increase with time, which is different from the elastic deformation in the early stage. It proves that plastic deformation and fracture trend of the sample begin to occur at this time.

(4) Local rupture stage (C-D segment): the axial stress crosses the peak and enters this phase. At this time, the axial stress decreases rapidly with the increase of time, and some brittle failure occurs in the sample and cracks begin to appear. At the same time, some cracking sounds can be heard externally. According 
to the microenergy theory, a large amount of heat is released from coal-rock at this stage, and the temperature inside the samples rises rapidly. The thermal stress intensifies the generation and evolution of cracks inside the samples [36] and further promotes the fracture trend of the samples.

(5) Complete rupture stage (D-E segment): at this stage, the axial stress dithers with the increase of time, accompanied by a large amount of heat release, and the thermal stress effect of the sample is more significant. At the same time, continuous cracking sound can be heard externally, which can be used to judge the further development of the crack in the test sample. Finally, the axial stress curve drops rapidly again. Meanwhile, the sound of severe fracture can be heard externally. Under the continuous combined action of external triaxial stress and internal thermal stress, the cracks run through the composite coalrock mass, and the sample ruptures completely.

Combined with the unloading rate, further comparison of the B-E section after unloading operation in Figure 3(a) shows that when the unloading rate increases from $0.05 \mathrm{MP} /$ $s$ to $0.10 \mathrm{MPa} / \mathrm{s}$ and $0.20 \mathrm{MPa} / \mathrm{s}$, the peak axial stress of composite coal-rock decreases from $50.910 \mathrm{MPa}$ to 47.715 $\mathrm{MPa}$ and $46.985 \mathrm{MPa}$ and the peak axial stress decreases with the increase of unloading rate. The results show that the peak axial stress of composite coal-rock decreases with the increase of unloading rate and the triaxial compressive strength decreases.

The triaxial compressive strength of 9 groups of tests is fitted by progressive analysis, and the unloading rate-triaxial compressive strength fitting curve is obtained as shown in Figure 3(b). It can be seen that the relationship between unloading rate and triaxial compressive strength is exponential, and the specific fitting relationship is shown as follows $\left(R^{2}=0.99\right)$ :

$$
\sigma_{k v}=46.9331+8.8913 e^{-13 v_{x}}
$$

where $\sigma_{k v}$ is the triaxial compressive strength affected by unloading rate, $\mathrm{MPa}$, and $v_{x}$ is the rate of relief confining pressure, $\mathrm{MPa} / \mathrm{s}$.

To verify the correctness of equation (1), under the same initial confining pressure of $10 \mathrm{MPa}, 6$ additional composite coal-rock samples T1-T6 (the sample conditions are exactly the same as those of the formal test samples) were selected and divided into two groups. T1-T3 were unloaded at $0.075 \mathrm{MPa} / \mathrm{s}$, and T4-T6 were unloaded at $0.15 \mathrm{MPa} / \mathrm{s}$. According to Figure 3(b) and equation (1), in the fitting relationship, when the unloading rate is $0.075 \mathrm{MPa} / \mathrm{s}$, the triaxial compressive strength is about $48.859 \mathrm{MPa}$, and when the unloading rate is $0.15 \mathrm{MPa} / \mathrm{s}$, the triaxial compressive strength is about $47.167 \mathrm{MPa}$. The unloading results of the verification experiment are shown in Table 4 , and " $\Delta$ " is marked in Figure 3(b). It can be seen from Table 4 that the deviation between the results of test samples T1-T6 and the deviation rates are less than $1 \%$, which fully proves the correctness of the fitting relation (1).
According to the fitting curve in Figure 3(b) and equation (1), there is a horizontal asymptote $\sigma_{k v}=\sigma_{j}$ in this fitting curve, and it intersects the vertical axis at a point $(0$, $\left.\sigma_{t}\right)$. Thus, equation (1) can be extended to

$$
\sigma_{k v}=\sigma_{j}+\left(\sigma_{t}-\sigma_{j}\right) e^{-13 v_{x}} \text {. }
$$

According to equation (2), when unloading rate $v_{x}$ approaches 0 , triaxial compressive strength $\sigma_{k v}$ is $\sigma_{t}$. At this time, the triaxial unloading process is similar to the conventional triaxial loading process, that is, the situation in the preexperiment. According to equation (1), $\sigma_{t}$ is $55.824 \mathrm{MPa}$, which is not far from the normal triaxial compressive strength of $51.997 \mathrm{MPa}$ in Table 1 and meets the conditions of equation (2).

As unloading rate $v_{x}$ approaches infinity, then triaxial compressive strength $\sigma_{k v}$ approaches $\sigma_{j}$. Under this condition, the unloading process is approximately a uniaxial loading process, and the compressive strength of the sample is $\sigma_{j} \mathrm{MPa} . \sigma_{j}$ is the uniaxial compressive strength. No matter how the unloading rate $v_{x}$ accelerates, the triaxial effect of confining pressure will always exist, and the triaxial compressive strength $\sigma_{k v}$ would always be greater than the uniaxial compressive strength $\sigma_{j}$, so $\sigma_{j}$ is an impossible limit case. So the values of the curves only approximate infinitely but never intersect. By expanding and finishing formula (2), the relationship between the unloading rate of composite coal-rock and the triaxial compressive strength in the unloading process can be obtained as follows:

$$
\sigma_{k v}=\sigma_{t}-\left(1-e^{-13 v_{x}}\right) \sigma_{\Delta}
$$

where $\sigma_{\Delta}$ is extreme difference, whose value is $\left(\sigma_{t}-\sigma_{j}\right) \mathrm{MPa}$. When the initial confining pressure is determined, its value is only related to the physical parameters of the material itself.

It can be seen from equation (3) that the unloading confining pressure rate will reduce the triaxial compressive strength of composite coal-rock, and the greater the unloading rate is, the more obvious the influence is on the triaxial compressive strength. Both of them show an exponential decay trend. The compressive strength of the sample under unloading is less than that under normal triaxial conditions.

3.2. Relationship between Initial Confining Pressure and Triaxial Compressive Strength. Figure 4 shows the stresstime curve and compressive strength variation trend curve of the triaxial test samples under the confining pressures of $10 \mathrm{MPa}, 15 \mathrm{MPa}$, and $20 \mathrm{MPa}$, respectively, at the unloading speed of $0.10 \mathrm{MPa} / \mathrm{s}$.

It can be seen from Figure 4(a) that the change of confining pressure does not change the stages of the timeaxial stress curve of the composite coal and rock, and the five stages of the above analysis can still be clearly seen. The unloading operation does not lead to a new stage, but it has a great influence on the axial stress peak of the sample. When the unloading rate remains at $0.1 \mathrm{MPa} / \mathrm{s}$, the initial confining pressure of samples $4 \# \sim 6 \#$ increases from $10 \mathrm{MPa}$ to $15 \mathrm{MPa}$ 
TABLE 4: Verification of experimental results.

\begin{tabular}{lccr}
\hline No. & Unloading rate $\left(\mathrm{MPa} \cdot \mathrm{s}^{-1}\right)$ & Triaxial compressive strength $(\mathrm{MPa})$ & Deviation rate \\
\hline T1 & 0.075 & 48.432 & 0.874 \\
T2 & 0.075 & 49.015 & 0.319 \\
T3 & 0.075 & 48.821 & 0.078 \\
T4 & 0.150 & 47.431 & 0.602 \\
T5 & 0.150 & 46.891 & 0.543 \\
T6 & 0.150 & 47.055 & 0.195 \\
\hline
\end{tabular}

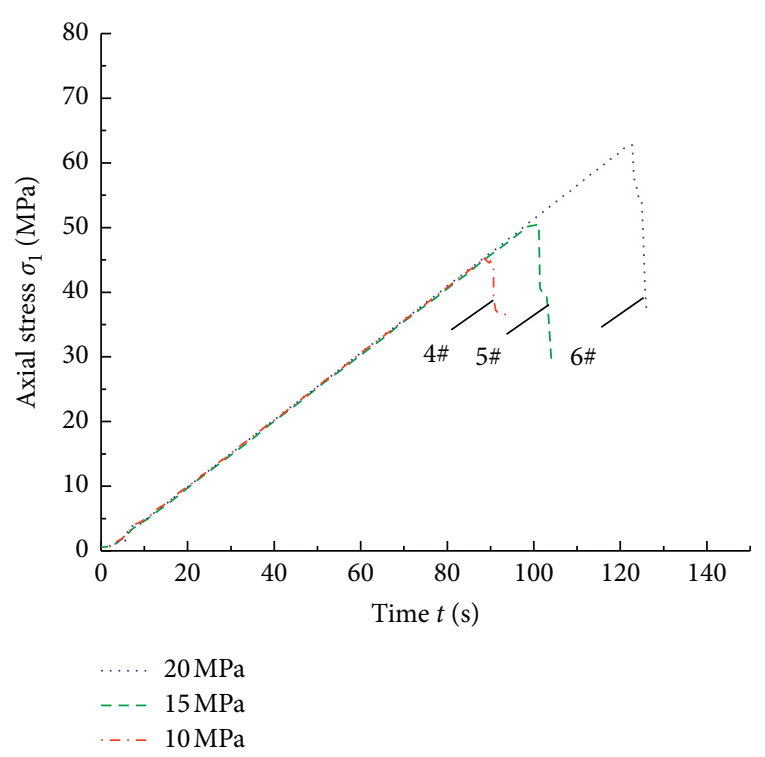

(a)

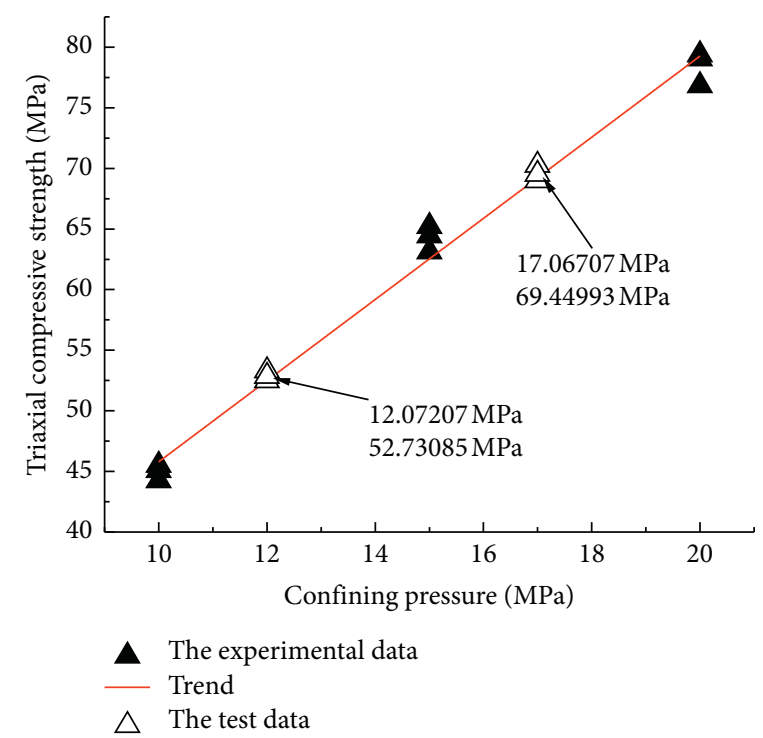

(b)

Figure 4: Stress path and compressive strength under different confining pressures. (a) Stress path of $4 \# \sim 6 \#$. (b) Triaxial compressive strength fitting curve.

and $20 \mathrm{MPa}$, and the peak axial stress increases from 45.497 $\mathrm{MPa}$ to $63.120 \mathrm{MPa}$ and $79.368 \mathrm{MPa}$, that is, the peak axial stress of coal-rock increases with the increase of confining pressure. In summary, the initial confining pressure will affect the triaxial compressive strength of the sample. The greater the initial confining pressure is, the higher the triaxial compressive strength will be.

The test results of 9 groups which finish under the condition of the same unloading rate and different confining pressures are fitted linearly, and the fitting curve of initial confining pressure-triaxial compressive strength is obtained as shown in Figure 4(b), and the relation of curves is shown as follows $\left(R^{2}=0.99\right)$ :

$$
\sigma_{k w}=13.324+3.347 \sigma_{30}
$$

where $\sigma_{k w}$ is the triaxial compressive strength affected by confining pressure, $\mathrm{MPa}$, and $\sigma_{30}$ is the initial confining pressure, MPa.

To verify the correctness of equations (4) and (6), additional composite coal-rock T7 $\sim$ T12 (sample conditions are exactly the same as those of the formal test) were selected and divided into two groups ( 3 in each group) to discharge at $0.1 \mathrm{MPa} / \mathrm{s}$ under the initial confining pressure of $12 \mathrm{MPa}$ and $17 \mathrm{MPa}$. According to Figure 4(b) and equation (4), in the fitting relationship, the triaxial compressive strength is about $52.731 \mathrm{MPa}$ when the initial confining pressure is $12 \mathrm{MPa}$ and about $69.450 \mathrm{MPa}$ when the initial confining pressure is $17 \mathrm{MPa}$. The unloading results of the verification experiment are shown in Table 5, and " $\Delta$ " is marked in Figure 4(b). As can be seen from Table 5, the deviation between the results of test samples $\mathrm{T} 7 \sim \mathrm{T} 12$ and the fitting point is less than $1 \%$ or near it, which fully proves the correctness of the fitting relation (4).

The composite coal-rock sample is a kind of composite rock material, so its failure criterion still conforms to Mohr-Coulomb (M-C) failure criterion. And the form of principal stress is shown as follows:

$$
\left\{\begin{array}{l}
\sigma_{1}=b+k \sigma_{3}, \\
b=\frac{2 c \cos \varphi}{1-\sin \varphi}, \\
k=\frac{1+\sin \varphi}{1-\sin \varphi},
\end{array}\right.
$$

where $\sigma_{1}$ is the compressive strength, $\mathrm{Pa} ; \sigma_{3}$ is the confining pressure, $\mathrm{Pa} ; b$ is the uniaxial compressive strength of the 
TABLE 5: Verification of experimental results.

\begin{tabular}{lccc}
\hline No. & $\begin{array}{c}\text { Initial confining } \\
\text { pressure }(\mathrm{MPa})\end{array}$ & $\begin{array}{c}\text { Triaxial compressive } \\
\text { strength }(\mathrm{MPa})\end{array}$ & $\begin{array}{c}\text { Deviation rate } \\
(\%)\end{array}$ \\
\hline T7 & 12 & 52.493 & 0.451 \\
T8 & 12 & 53.302 & 1.083 \\
T9 & 12 & 52.845 & 0.216 \\
T10 & 17 & 70.251 & 1.153 \\
T11 & 17 & 68.987 & 0.667 \\
T12 & 17 & 69.521 & 0.102 \\
\hline
\end{tabular}

material, $\mathrm{Pa} ; k$ is the influence coefficient of confining pressure on axial pressure; $c$ is the cohesive force, $\mathrm{Pa}$; and $\varphi$ is the internal friction angle, .

According to the M-C failure criterion, when the confining pressure $\sigma_{3}$ changes, the overall compressive strength of the composite coal-rock also changes. When confining pressure is removed at the unloading rate of $v_{x}(t)$, the relationship between triaxial compressive strength and initial confining pressure is shown as follows:

$$
\sigma_{k w}=b+k\left(\sigma_{30}-v_{x}(t) t\right),
$$

where $t$ is the acting time of confining pressure, $\mathrm{s}$, and $v_{x}$ is the unloading rate, $\mathrm{MPa} / \mathrm{s}$. When the unloading rate $v_{x}$ is 0 , it is equivalent to the normal triaxial loading process. It can be expanded and sorted into the form shown as follows:

$$
\sigma_{k w}=\left(b-v_{x}(t) t\right)+k \sigma_{30} .
$$

The relationship between initial confining pressure and compressive strength of composite coal-rock under a certain unloading rate is shown as follows:

$$
\left\{\begin{aligned}
\sigma_{k w} & =b^{\prime}+k \sigma_{30}, \\
b^{\prime} & =f\left(b, v_{x}\right),
\end{aligned}\right.
$$

where $b^{\prime}$ is a variable related to its own properties and unloading rate. When the unloading rate is constant, $b^{\prime}$ is a constant, and its value is $\left(b-v_{x}(t) t\right)$.

According to equation (8) and Figure 4(b), when other factors are in the same condition, the increase in initial confining pressure results in a strengthening in triaxial compressive strength, and the relationship between them is linear.

3.3. Failure Criterion of Composite Coal-Rock. Equations (3) and (8) represent the relationship between unloading rate or initial confining pressure and the compressive strength of composite coal-rock. The following is to derive the relationship between the combined action of the two and the compressive strength.

According to the M-C failure criterion of equation (5), the constant triaxial compressive strength $\sigma_{t}$ in equation (3) can be expressed as follows:

$$
\sigma_{t}=b+k \sigma_{30} .
$$

The normal triaxial compressive strength is about 35\% higher than the uniaxial compressive strength. As mentioned above, the confining pressure of unloading starting point is generally $70 \%-80 \%$, which is equivalent to $94.5 \%-$ $108 \%$ of uniaxial compressive strength. Furthermore, the ultimate strength $\sigma_{j}$ in equation (3) can be approximated as the axial stress at the starting point of unloading and is a certain value. A coefficient $\gamma$ is defined as a proportional coefficient, which satisfies the following relation:

$$
\sigma_{j}=\gamma \sigma_{30} .
$$

Furthermore, equation (3) can be expressed as follows:

$$
\sigma_{k}=\left(b+k \sigma_{30}\right)-\left(1-e^{-13 v_{x}}\right)\left(b+k \sigma_{30}-\gamma \sigma_{30}\right) \text {. }
$$

By expanding equation (11) and arranging it in the form of equation (9), the following form can be obtained:

$$
\sigma_{k}=b \cdot e^{-13 v_{x}}+\left[k \cdot e^{-13 v_{x}}+\left(1-e^{-13 v_{x}}\right) \gamma\right] \sigma_{30},
$$

where $\sigma_{k}$ is the triaxial compressive strength, $\mathrm{MPa}$, and the first term corresponds to $b^{\prime}$ in equation (8).

By combining equation (12) with equation (5), the failure criteria of composite coal-rock under unloading conditions can be obtained as follows:

$$
\left\{\begin{aligned}
\sigma_{k} & =b \cdot e^{-13 v_{x}}+\left[k \cdot e^{-13 v_{x}}+\left(1-e^{-13 v_{x}}\right) \gamma\right] \sigma_{30} \\
b & =\frac{2 c \cos \varphi}{1-\sin \varphi} \\
k & =\frac{1+\sin \varphi}{1-\sin \varphi}
\end{aligned}\right.
$$

\section{The Influence of Different Unloading Conditions on Deformation}

4.1. Influence of Unloading Rate on Deformation. Figure 5 shows the stress-strain curve of composite coal-rock samples $1 \# \sim 3 \#$ during the whole process of the test, where $\varepsilon$ is the axial strain, $\sigma_{1}$ is the axial stress, and the dashed horizontal line in the figure represents the starting point of relief confining pressure. It can be seen from Figure 5 that the stress-strain curve in the unloading process can still be divided into five stages as described above: compaction, single elasticity, unloading elastic-plastic, local fracture, and complete fracture.

In Figure 5, compared with the stress-time curve in Figure 3 , the compaction phase (O-A) section is not obvious, and no obvious strain changes are observed. According to the above analysis, in this stage, the fine cracks existing in the main compacted sample and the gaps between the coal and rock generate very small deformation, so no obvious changes are observed on the stress-strain curve.

By comparing and analyzing the single elastic stage (A$B$ ), it can be seen that the stress-strain curves of the three groups of samples are linear before the unloading starting point, and the samples are in a state of constant triaxial compression. In addition, the elastic modulus remains 

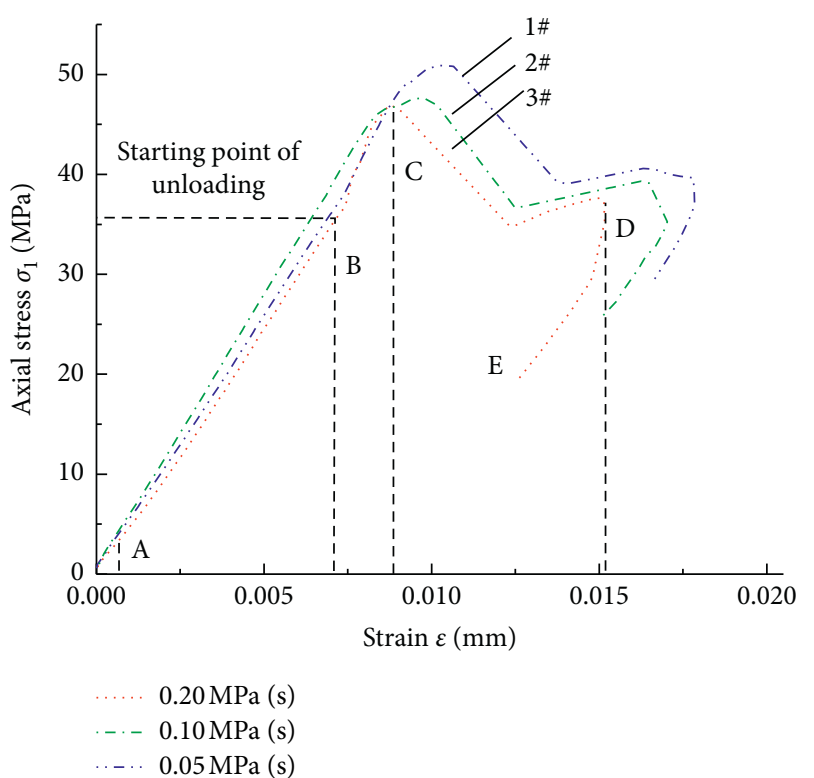

FIGURE 5: Stress-strain curves at different unloading rates.

constant, proving that it satisfies the characteristics of Hooke's law.

Before and after the unloading elastic-plastic stage (B-C), the curve has a slight up, and the slope of the curve increases but remains linear at the initial stage. It proves that the sample is still in the elastic stage and is still elastic deformation. As the composite coal-rock can be regarded as composite materials, the elastic modulus of it can be determined by the mixing law of the following equation:

$$
\left\{\begin{array}{l}
E=E_{\text {coal }} \cdot V_{\text {coal }}+E_{\text {rock }} \cdot V_{\text {rock }}, \\
V_{\text {coal }}+V_{\text {rock }}=1,
\end{array}\right.
$$

where $E$ is the overall elastic modulus of coal-rock, N/m ${ }^{2}$; $E_{\text {coal }}$ is the elastic modulus of coal, N/m $\mathrm{m}^{2} ; E_{\text {rock }}$ is the elastic modulus of rock, $\mathrm{N} / \mathrm{m}^{2} ; V_{\text {coal }}=(1 / 3)$, which is the combined ratio of coal to coal-rock; and $V_{\text {rock }}=(2 / 3)$, which is the combination ratio of rock to coal-rock.

According to equation (14), the elastic modulus $E$ of the sample as a whole should be closer to the rock due to the large proportion of rock, and the overall mechanical properties also should be more similar to the rock. However, in practice, the test sample is composed of splices, and its combination is not uniform, so it differs from the theoretical curve. A marked inflection point can be seen on the curve. The elastic modulus $E_{y a n}$ and compressive strength of rock are both greater than those of coal $E_{m e i}$. Therefore, when the axial stress of the sample reaches the coal's stress, the rock's stress does not arrive and is still in the elastic section. Although the confining pressure inhibited the horizontal deformation of the coal and increased the compressive strength, making the sample elastic deformation, the overall elastic modulus $E$ of the sample decreased because the coal had entered the yield stage. Eventually, this causes a change in the slope of the stress-strain curve.

The prepeak stress curve of the B-C section is very short and nonlinear, which shows the yield characteristic overall.
At the same time, it can be seen that the process is further shortened with the increase of the release confining pressure rate. In addition, the stress peak strains at point $\mathrm{C}$ are around 0.01 at different unloading rates. Although confining pressure can inhibit coal fracture, there is a limit of inhibition due to the physical parameters of coal itself.

According to the preliminary results [37-39], it can be seen from both experiment and numerical simulation that when the composite coal-rock enters the unloading stage, the coal has entered the yield stage and has a tendency to produce a large number of cracks, while the rock is still in the elastic stage for a long time, and the compressive strength is significantly higher than the coal. Combined with the experimental results of this study, it can be seen that only cracks can be seen in the coal during the final fracture, and no penetrating cracks can be seen in the whole sample. Therefore, the analysis of the force in the coal is more conducive to exploring the cause of cracks. In order to study the evolution trend of fractures, point $P$ was taken from the coal for stress decomposition during unloading, as shown in Figure 6.

The confining pressure $\sigma_{2}$ and $\sigma_{3}$ are the same all the time, and the direction of the resultant force $\sigma_{a}$ remains unchanged and its magnitude decreases with the release of confining pressure $\sigma_{c}$. In addition, the axial stress $\sigma_{1}$ of coalrock increases continuously, resulting in the increase of resultant force $\sigma_{a}$, and the vertical angle of resultant force $\sigma_{a}$ decreases. The above reasons make the axial compression deformation suppression gradually decreased. If the unloading rate increases, the process of coal tending to fracture will also be accelerated, resulting in an obvious overall yield process. Therefore, the nonlinear trend is obvious on the whole stress-strain curve, and the faster the trend is, the more obvious it is.

It can be seen from the C-E curve that the strain of the samples increases rapidly. During the test, it can be seen that 


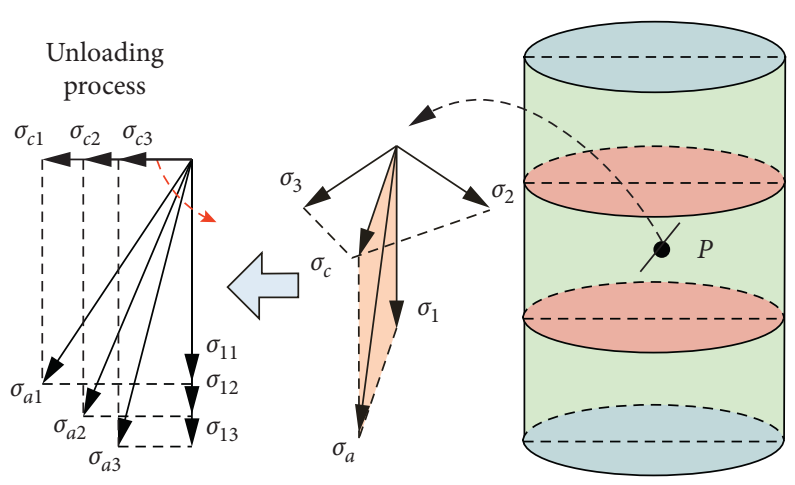

Figure 6: Trend of stress in coal during the test.

the specimen has obvious deformation and finally produces penetrating cracks after point $\mathrm{D}$. The secondary peak value at point $\mathrm{D}$ is caused by the development of local fractures into perforating fractures. The strain of the D-E segment decreases with the decrease of stress, and the obvious springback can be seen on the curve.

Figure 7 shows the test results of $1 \# \sim 3 \#$ under the same confining pressure and different unloading rates. It can be seen from Figure 7 that the cracks of the samples mainly exist in the coal, and the rock mass has microfracture, but it is not obvious. According to equation (14) and accepted literature, it can be seen that the triaxial compressive strength of composite coal-rock is significantly lower than that of rock. When the sample is broken, the rock is still in the elastic stage, so the strain of rock decreases at the same time when the axial stress decreases. At the moment, the coal has been completely broken and its strain is almost constant, so the overall stress-strain curve bounces back.

\subsection{Effect of Initial Confining Pressure on Deformation} Characteristics. Figure 8 shows the mechanical variation curve of $4 \# \sim 6 \#$ samples under different confining pressures $(10 \mathrm{MPa}, 15 \mathrm{MPa}$, and $20 \mathrm{MPa})$ at the same rate of $0.1 \mathrm{MPa} / \mathrm{s}$. The arrow in the figure is the starting point of unloading.

According to the analysis of Figure 8, the stress-strain curves of all samples are the same in stages as in Figure 5. The change of confining pressure does not lead to stage changes, and the peak strain of the three curves is around 0.01 . According to the comparison of the curves, the increase of confining pressure not only increases the axial stress of the sample but also increases the slope of the elastic stage and the springback after fracture.

The deformation of the composite coal-rock is caused by the joint action of three-direction stress. The single elastic stage is in the early stage of the test process, at which the axial pressure effect is lower than the confining pressure effect. In order to produce the same axial strain, the axial pressure must be increased to resist the horizontal strain caused by confining pressure. And the greater the confining pressure, the greater the requirement for axial stress $\sigma_{1}$. Thus, it can be seen that the slope increases on the stress-strain curve in Figure 8. When the unloading rate remains unchanged, the greater the initial confining pressure is, the greater the confining pressure acting on coal-rock in the same period of time is, and the stronger the restraining effect on deformation is.

The triaxial process of composite coal-rock is a thermodynamic process [40]. Assuming that there is no heat exchange with the outside world in the loading process, the work done by the triaxial stress on the sample in the loading and unloading process $W$ is equal to the change in the internal energy of the sample $U$. The relationship between them is

$$
\begin{aligned}
W & =U=U_{e}+U_{d}, \\
& =U_{e}+\sum U_{d i},
\end{aligned}
$$

where $U_{e}$ is elastic strain energy, $U_{d}$ is dissipated energy, and $U_{d i}$ is dissipated energy in various forms, and $U_{d i}$ refers to various forms of dissipated energy, which accounts for a small proportion of $4.71-26.06 \%$ before the peak of triaxial stress, but a large proportion of more than $80 \%$ after the peak [41]. Dissipated energy mainly manifests in plastic deformation and a small amount of electromagnetic, thermal, and others.

Under triaxial loading, confining pressure and axial pressure work on the sample at the same time, and the change of internal energy $U$ of coal-rock is

$$
\begin{aligned}
U & =\int \sigma_{1} \mathrm{~d} \varepsilon_{1}+2 \int \sigma_{3} \mathrm{~d} \varepsilon_{3}, \\
& =\sum_{i=1}^{n} \frac{1}{2}\left(\sigma_{1 i}+\sigma_{1(i-1)}\right)\left(\varepsilon_{1 i}-\varepsilon_{1(i-1)}\right)-2 \sum_{i=1}^{n} \sigma_{3}\left(\varepsilon_{3 i}-\varepsilon_{3(i-1)}\right),
\end{aligned}
$$




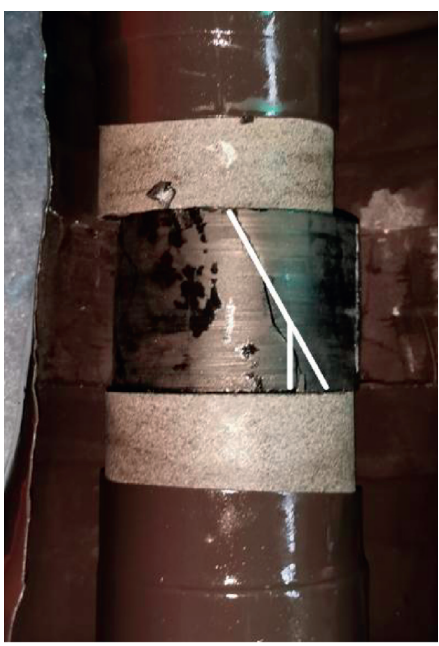

(a)

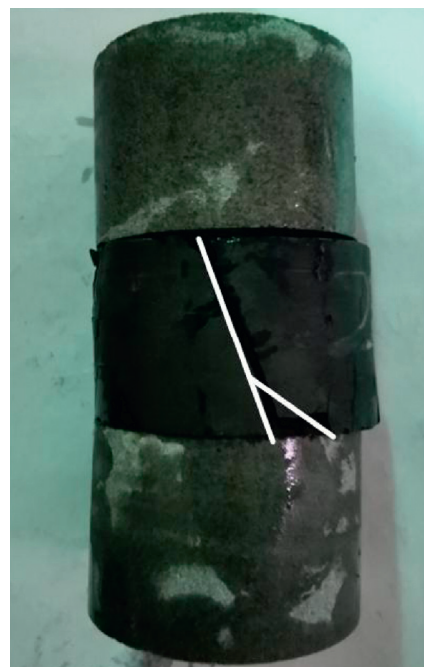

(b)

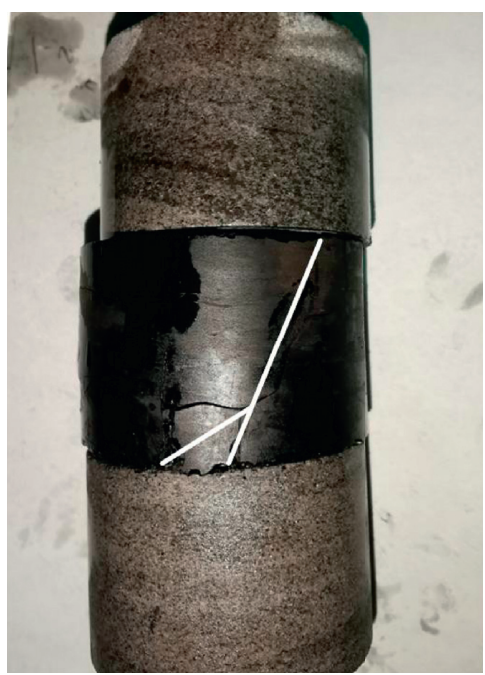

(c)

Figure 7: The results of $1 \# \sim 3 \#$. (a) 1\#, (b) 2\#, and (c) 3\#.

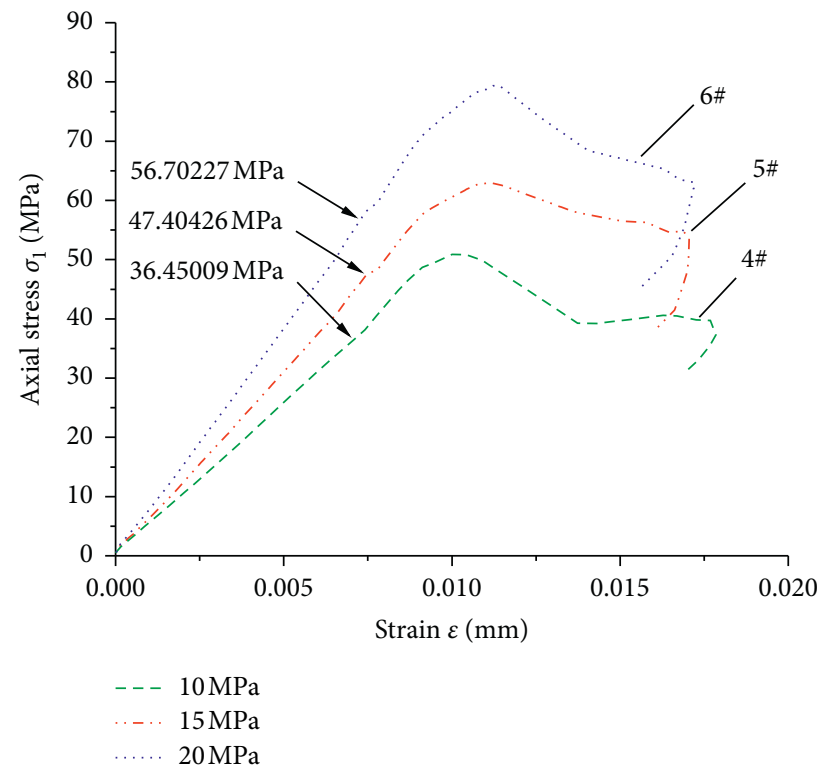

FIGURE 8: Stress-strain curves under different confining pressures.

where $\sigma_{1}$ and $\sigma_{3}$, respectively, are axial and confining pressures, $\mathrm{MPa}$, and $\varepsilon_{1}$ and $\varepsilon_{3}$ are axial strain and lateral strain, respectively. $\sigma_{1 i}, \sigma_{3 i}, \varepsilon_{1 i}$, and $\varepsilon_{3 i}$ are, respectively, the values of the $i$ th point on the stress-strain curve.

It can be seen from the literature $[41,42]$ that the confining pressure has little or even negligible effect on the elastic strain energy $U_{e}$ under triaxial loading. Therefore, the calculation formula of the elastic strain energy $U_{e}$ is consistent with that under uniaxial and is proportional to the square of the axial compression $\sigma_{1}$. As mentioned above, before loading to the stress peak, the proportion of dissipated energy $U_{d}$ in the sample is very small, so the variation trend of the internal energy $U$ of the sample is consistent with that of the elastic strain energy $U_{e}$.
As can be seen from Figure 8, with the increase of initial confining pressure, the triaxial compressive strength increases. Before the stress peak, the elastic strain energy $U_{e}$ of the composite coal-rock samples under various confining pressures increases with the increase of confining pressure $\sigma_{3}$. So the greater the change of internal energy $U$ is, the more energy is accumulated in the coal-rock.

Figure 9 shows the test results of samples $4 \# \sim 6 \#$ under the same unloading rate and different confining pressures. It can be seen that there were inverted " $\mathrm{Y}$ " shaped splitting cracks in the coal after fracture of samples under various confining pressures, with similar final strain and the same state. After the end of the experiment, the sample is in the same environment without the action of three-phase external force, so it can be considered that the internal energy 


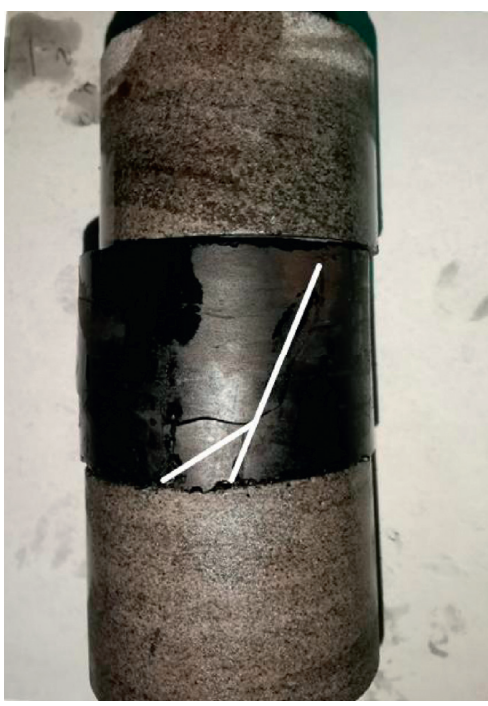

(a)

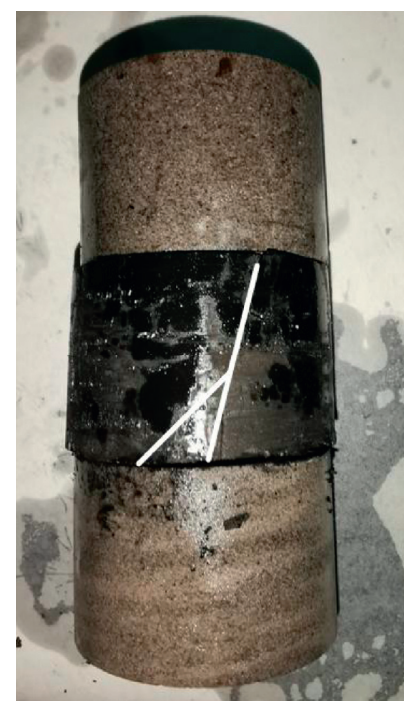

(b)

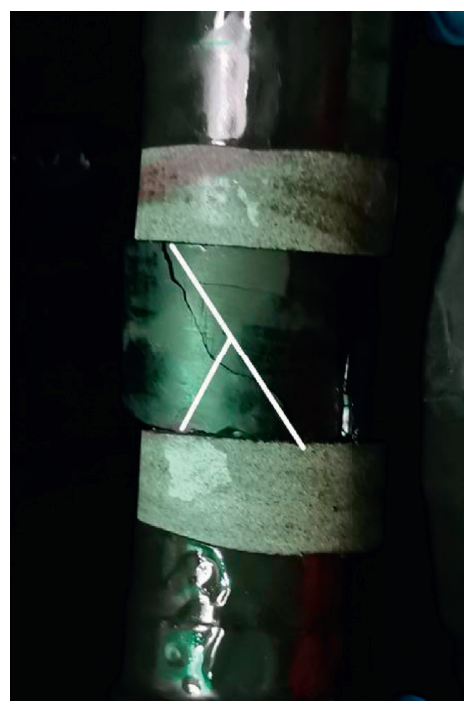

(c)

Figure 9: The results of $4 \# \sim 6 \#$. (a) $4 \#$, (b) 5\#, and (c) $6 \#$.

of the final sample is approximately the same, that is, the energy contained in the final state is approximately the same. Therefore, it can be seen that the larger the confining pressure $\sigma_{3}$ is at the fracture stage, the more dissipated energy released by the sample is, resulting in the more severe the fracture of the composite coal-rock. And it leads to the phenomenon that the larger the initial confining pressure is, the more obvious the rebound effect is.

\section{Conclusions}

Triaxial unloading tests were carried out for the composite coal-rock with a combination ratio of $1: 1: 1$ under the conditions of different discharge confining pressure rates and different initial confining pressures. By analyzing the experimental data, it can be seen that the unloading process of composite coal and rock can be divided into five stages: compaction, single elasticity, unloading elastic-plastic, local fracture, and complete fracture. The coal and rock fracture is brittle, and different unloading conditions do not change the overall stage.

The failure criterion of complex coal-rock unloading is derived. There is a negative exponential relationship between unloading rate and triaxial compressive strength; the higher the rate, the lower the compressive strength. The relationship between initial confining pressure and compressive strength is linear. The greater the initial confining pressure is, the greater the compressive strength is.

In triaxial unloading, the peak strain $\varepsilon$ of the composite coal-rock is all around 0.01 . The unloading rate has little influence on the strain variation trend, and the initial confining pressure has a more obvious influence on it. The higher the initial confining pressure is, the higher the slope of the elastic section of the strain curve, the greater the elastic modulus is. Meanwhile, the larger the peak value of the axial stress $\sigma_{1}$ in unloading is, the larger the total energy is and the more energy is released when it reaches the steady state, and the more obvious the rebound effect after fracture is.

\section{Data Availability}

The test data used to support the findings of this study are available from the corresponding author upon request.

\section{Conflicts of Interest}

The authors declare that they have no conflicts of interest.

\section{Acknowledgments}

This work was supported by the discipline innovation team of Liaoning Technical University (LNTU20TD-29), Chinese National Natural Science Foundation (nos. 51604141 and 51204087), and Liaoning Provincial Education Committee Projects (LJ2019JL013 and LJ2020JCL020).

\section{References}

[1] Y.S. Pan, "Integrated study on compound dynamic disaster of coal-gas outburst and rockburst," Journal of China Coal Society, vol. 41, no. 1, pp. 105-112, 2016.

[2] X. B. Wang, Y. S. Pan, and Z. H. Zhang, "Preliminary numerical simulation of zonal disintegration phenomenon based on loading and unloading models and the mechanism of spatial strain localization," Journal of Lianing Technical University(Natural Science), vol. 31, no. 2, pp. 1-7, 2012.

[3] F. Gao, K.-P. Zhou, X.-W. Luo, and J.-B. Zhai, "Effect of induction unloading on weakening of rock mechanics properties," Transactions of Nonferrous Metals Society of China, vol. 22, no. 2, pp. 419-424, 2012.

[4] Q. S. Liu, K. D. Liu, X. L. Lu, and J. B. Zhu, "Study of mechanical properties of raw coal under high stress with triaxial unloading," Chinese Journal of Rock Mechanics and Engineering, vol. 33, no. S2, pp. 3429-3438, 2014. 
[5] H. Y. Rong, G. C. Li, G. M Zhao, and J. L. Liang, "True triaxial test study on mechanical properties of deep rock mass in different stress paths," Journal of China Coal Society, vol. 45, no. 9, pp. 3140-3149, 2020.

[6] Z. Zhou and Z. Chen, "Parallel offset crack interactions in rock under unloading conditions," Advances in Materials Science and Engineering, vol. 2019, Article ID 1430624, 18 pages, 2019.

[7] T. Qin, Y. Duan, H. Sun, H. Liu, and L. Wang, "Energy evolution and acoustic emission characteristics of sandstone specimens under unloading confining pressure," Shock and Vibration, vol. 2019, Article ID 1612576, 9 pages, 2019.

[8] X. Ni, X. Shen, and Z. Zhu, "Mechanical and acoustic emission characteristics of sandstone through triaxial unloading test after cyclic freezing-thawing treatment," $A d$ vances in Civil Engineering, vol. 2020, Article ID 7150536, 12 pages, 2020.

[9] T. Han, J. Shi, and Y. Chen, "Mechanical characteristics and failure characteristics of jointed rock under axial unloading and radial unloading," Advances in Civil Engineering, vol. 2020, Article ID 8812621, 15 pages, 2020.

[10] Y. Wang, W. K. Feng, and C. H. Li, "On anisotropic fracture and energy evolution of marble subjected to triaxial fatigue cyclic-confining pressure unloading conditions," International Journal of Fatigue, vol. 134, Article ID 105524, 2020.

[11] Z. Zhang, X. Yu, and M. Deng, "Damage evolution of sandy mudstone mechanical properties under mining unloading conditions in gob-side entry retaining," Geotechnical and Geological Engineering, vol. 37, no. 4, pp. 3535-3545, 2019.

[12] J. Li, F. Lin, H. Liu, and Z. Zhang, “Triaxial experimental study on changes in the mechanical properties of rocks under different rates of confining pressures unloading," Soil Mechanics and Foundation Engineering, vol. 56, no. 4, pp. 246252, 2019.

[13] K. Wang and F. Du, "Experimental investigation on mechanical behavior and permeability evolution in coal-rock combined body under unloading conditions," Arabian Journal of Geosciences, vol. 12, p. 422, 2019.

[14] K. G. Li, B. W. Yang, and Q. C. Qin, "Experimental study on unloading damage and permeability of dolomite based on nuclear magnetic resonance technique," Chinese Journal of Rock Mechanics and Engineering, vol. 38, no. S2, pp. 34933502, 2019.

[15] Y. R. Li, Q. Yan, M. Li, Y. B. Lou, and Y. Li, "Study on the law of loading stress of soft and hard Rock," Hydro Science and Cold Zone Engineering, vol. 2, no. 2, pp. 53-58, 2019.

[16] H. F. Sun, Y. M. Yang, Y. Ju, Q. G. Zhang, and R. D. Peng, "Numerical analysis of deformation, failure and energy release mechanisms of fractured coal rock under unloading conditions," Journal of China Coal Society, vol. 39, no. 2, pp. 258-272, 2014.

[17] Y. B. Cai, K. Wang, L. Yuan, C. Xu, Q. Fu, and D. L. Kong, "Numerical simulation and verification of unloading damage evolution characteristics of coal and rock mass during deep mining," Journal of China Coal Society, vol. 44, no. 5, pp. 1527-1535, 2019.

[18] X. Ni, X. Shen, and Z. Zhu, "Microscopic characteristics of fractured sandstone after cyclic freezing-thawing and triaxial unloading tests," Advances in Civil Engineering, vol. 2019, Article ID 6512461, 11 pages, 2019.

[19] X.-Y. Zhu, X.-D. Chen, and F. Dai, "Mechanical properties and acoustic emission characteristics of the bedrock of a hydropower station under cyclic triaxial loading," Rock
Mechanics and Rock Engineering, vol. 53, no. 11, pp. 52035221, 2020.

[20] L. Wu, X. Xiang, Y. Chen, K. Ali, J. Zhou, and M. Chen, "Modeling and simulation of dynamic unloading of prestressed rockmass," Computer Modeling in Engineering \& Sciences, vol. 120, no. 2, pp. 421-443, 2019.

[21] X. Zhou, Q. Qian, and Y. Zhang, “The constitutive relation of crack-weakened rock masses under axial-dimensional unloading," Acta Mechanica Solida Sinica, vol. 21, no. 3, pp. 221-231, 2008.

[22] J.-S. Sun, Q.-H. Zhu, and W.-B. Lu, "Numerical simulation of rock burst in circular tunnels under unloading conditions," Journal of China University of Mining and Technology, vol. 17, no. 4, pp. 552-556, 2007.

[23] Y. R. Yang, H. Q. Xie, and M. L. Xiao, "Deformation failure and energy characteristics of transverse-isotropic rock under unloading of high confining pressure," Chinese Journal of Geotechnical Engineering, vol. 36, no. 8, pp. 1999-2006, 2017.

[24] D. Li, Z. Sun, T. Xie, X. Li, and P. G. Ranjith, "Energy evolution characteristics of hard rock during triaxial failure with different loading and unloading paths," Engineering Geology, vol. 228, pp. 270-281, 2017.

[25] X. G. Wang, B. Hu, H. M. Tang, X. L. Hu, J. D. Wang, and L. Huang, "A constitutive model of granite shear creep under moisture," Journal of Earth Science, vol. 27, no. 04, pp. 667-685, 2016.

[26] L. F. Fan and L. N. Y. Wong, "Stress wave transmission across a filled joint with different loading/unloading behavior," International Journal of Rock Mechanics and Mining Sciences, vol. 60, no. 8, pp. 227-234, 2013.

[27] Y. Wang, Q. H. Zhao, Y. G. Xiao, and Z. Q. Hou, "Influence of time-lagged unloading paths on fracture behaviors of marble using energy analysis and post-test CT visualization," Environmental Earth Sciences, vol. 79, no. 10, p. 217, 2020.

[28] M. Zhang, Q. Meng, and S. Liu, "Energy evolution characteristics and distribution laws of rock materials under triaxial cyclic loading and unloading compression," Advances in Materials Science and Engineering, vol. 2017, Article ID 5471571, 16 pages, 2017.

[29] R. Yang, D. Ma, and Y. Yang, "Experimental investigation of energy evolution in sandstone failure during triaxial unloading confining pressure tests," Advances in Civil Engineering, vol. 2019, Article ID 7419752, 11 pages, 2019.

[30] X. X. Huo, "Acoustic characteristics of unloading failure and deformation failure mechanism of coal-rock," Mineral Engineering Research, vol. 35, no. 01, pp. 65-68, 2020.

[31] Fairhurst and Hudson, "Draft ISRM suggested method for the complete stress-strain curve for intact rock in uniaxial compression," International Journal of Rock Mechanics and Mining Sciences, vol. 36, no. 3, pp. 281-289, 1999.

[32] Z. Yang, Q. J. Qi, X. Li, and Z. R. Tong, "Numerical simulation by using FLAC3D and experiment of composite coal rock in fracture under load," Journal of Safety and Environment, vol. 17, no. 3, pp. 901-906, 2017.

[33] M. Z. Zhu, Study on Deformation and Failure Mechanism of Coal and Rock under Unloading Conditions, China University of Mining and Technology, Beijing, China, 2019.

[34] A. B. Jin, L. J. Wei, Y. Q. Zhao, B. X. Wang, H. Sun, and Y. D. Wei, "Mechanical characteristics analysis of granite under unloading conditions," Rock and Soil Mechanics, vol. 40, no. S1, pp. 459-467, 2019.

[35] Y. S. Pan, H. Luo, Z. H. Li, Y. F. Zhao, and X. C. Xiao, "Experimental study on gas permeability and charge induction of gaseous coal rock under confining pressure 
unloading," Chinese Journal of Rock Mechanics and Engineering, vol. 34, no. 4, pp. 713-719, 2015.

[36] L. F. Fan, J. W. Gao, Z. J. Wu, S. Q. Yang, and G. W. Ma, “An investigation of thermal effects on micro-properties of granite by X-ray CT technique," Applied Thermal Engineering, vol. 140, pp. 505-519, 2018.

[37] Z. Yang, X. P. Su, and X. Li, "Stress-charge-temperature coupling model of composite coal-rock in deformation and fracture," Journal of China Coal Society, vol. 44, no. 9, pp. 2733-2740, 2019.

[38] X. Li, H. Li, Z. Yang, X. P. Su, and Z. Y. Ma, "Temperature, tress, electromagnetic multi-field coupling mechanism of composite coal-rock deformation and fracture," Journal of China Coal Society, vol. 45, no. 5, pp. 1764-1772, 2020.

[39] X. Li, H. Li, Z. Yang, X. Wang, and W. Wang, "Numerical simulation case study by using FLAC-3D of the composite coal-rock on the load-free fracture," Journal of Safety and Environment, vol. 20, no. 6, pp. 2187-2195, 2020.

[40] L. F. Fan, Z. J. Wu, Z. Wan, and J. W. Gao, "Experimental investigation of thermal effects on dynamic behavior of granite," Applied Thermal Engineering, vol. 125, pp. 94-103, 2017.

[41] Z. Q. Ma, Y. D. Jiang, Y. W. Li, Y. M. Yang, and H. T. Li, "Experimental research on influence of loading rate and confining pressure on energy evolution of coal," Chinese Journal of Geotechnical Engineering, vol. 38, no. 11, pp. 2114-2121, 2016.

[42] D. Huang, R. Q. Huang, and Y. X. Zhang, "Experimental investigation on static loading rate effects on mechanical properties and energy mechanism of coarse crystal grain marble under uniaxial compression," Chinese Journal of Rock Mechanics and Engineering, vol. 31, no. 2, pp. 245-255, 2012. 